\title{
Liver abscess due to an unusual strain of Yersinia enterocolitica
}

\author{
JUDITH FOTHERGILL \\ M.R.C.P.
}

\author{
A. E. J. L. Mulira \\ F.R.C.S.
}

\author{
M. B. SKIRROW \\ M.B., Ph.D., F.R.C.Path. \\ Worcester Royal Infirmary, Worcester WRI $3 A S$
}

\begin{abstract}
Summary
A 46-year-old man with long standing diabetes mellitus suffered a spontaneous liver abscess due to an unusual strain of Yersinia enterocolitica (biotype 3, serotype 05). Isotope and ultrasound scans were particularly valuable in the diagnosis and management of a difficult clinical problem.
\end{abstract}

\section{Case report}

A Caucasian man aged 46 years presented in December 1979 with a 3-week history of malaise, anorexia, vomiting and weight loss. Two days before admission he had suffered rigors. He had been an insulin-dependent diabetic for 20 years and had developed peripheral arteriopathy, neuropathy, retinopathy, nephropathy and anaemia. For several years he had suffered intermittent ulceration and staphylococcal infections of his right foot.

On examination he looked pale and ill. He was afebrile, dehydrated, and had a large infected ulcer on the sole of his right foot. Nothing abnormal was found on abdominal examination. His haemoglobin was $9 \cdot 1 \mathrm{~g} / \mathrm{dl}$ with normal indices, but the serum iron and iron-binding capacity was depressed. His white cell count was $15.8 \times 10^{9} / 1$ of which $92 \%$ were neutrophils. His creatinine clearance was $35 \mathrm{ml} / \mathrm{min}$.

During the next few weeks his illness followed a remittent course but there was an overall deterioration, he became insulin resistant, and his haemoglobin fell to $6 \mathrm{~g} / \mathrm{dl}$. Seven weeks after admission his temperature rose to $40 \cdot 3^{\circ} \mathrm{C}$, his liver became palpably enlarged, and there was evidence of disturbed liver function: alkaline phosphatase 638 i.u./l (normal 30-130 i.u./l); 5-nucleotidase 47 units (normal 3-15 u.); serum albumin $20 \mathrm{~g} / \mathrm{l}$ (normal 35-50 g/l); serum globulin $46 \mathrm{~g} / \mathrm{l}$ (normal $18-36 \mathrm{~g} / \mathrm{l}$ ). Serum bilirubin, and serum glutamic oxaloacetic and glutamic pyruvate transaminases were normal. Isotope and ultrasound scans showed a large irregular cavity in the right lobe of his liver from which $150 \mathrm{ml}$ of green pus were later drained through a right subcostal incision under cover of benzyl penicillin, gentamicin, and metronidazole. Culture of the pus yielded a pure growth of $Y$. enterocolitica which was resistant to ampicillin but sensitive to tetracycline and gentamicin. By this time the organism was also growing in two of five blood cultures taken 3 days before operation (retrospectively, an incompletely identified Gram-negative bacillus isolated from one of nine blood cultures taken shortly after admission was probably this organism). Treatment with gentamicin was continued for 6 days, but then stopped because the patient developed a rash.

The patient made a slow recovery complicated by an attack of herpes zoster of his trunk 8 weeks after operation. Nine months later his wound had healed, there was no evidence of liver enlargement, and his general condition was judged to have returned to its former state.

The identity of the organism was confirmed by Dr N. S. Mair, of the Leicester Public Health Laboratory, and found to be of biotype 3, serotype 05 . The patient's serum agglutinated the organism to a titre of 160 .

\section{Discussion}

Infections with the Gram-negative bacillus Yersinia enterocolitica usually take the form of an acute terminal ileitis or ileocolitis. Such infections have an uneven geographical distribution (Fallon, 1979). The highest reported incidences are from Scandinavia, Belgium and eastern Europe, and most of these strains are of biotype 4, serotype 03. In England and Wales only 100 infections were reported in the period 1975-80, 46 of them in 1980 (Communicable Disease Surveillance Centre (Public Health Laboratory Service), unpublished). There was only one other recorded case of liver abscess: a man aged 61 years who also had diabetes and who was also infected with a biotype 3 , serotype 05 strain. Bouza et al. 
(1980) list six other cases of liver abscess in their review of $Y$. enterocolitica septicaemia, and each of these patients had either diabetes or cirrhosis. During 10 years experience of typing $Y$. enterocolitica in Britain only three other infections with biotype 3, serotype 05 strains - all in compromised patientswere encountered (Dr N. S. Mair, personal communication).

The source of our patient's organism is unknown. He had not been abroad and his only animal contact was with a pet dog that had died in old age 6 months before his illness began. The course of his illness fits the pattern described by Perera, Kirk and Noone (1980) for patients with liver abscess.

\section{Acknowledgment}

We thank Dr D. M. Hill for permission to report this patient who was admitted under his care, Dr N. S. Mair for typing the organism, and Dr N. S. Galbraith for permission to quote data collected by the Communicable Disease Surveillance Centre.

\section{References}

Bouza, E., Dominguez, A., Meseguer, M., Buzon, L., Boixeda, D., Revillo, M.J., Rafael, L. De \& MartinezBeltran, J. (1980) Yersinia enterocolitica septicaemia. American Journal of Clinical Pathology, 74, 404.

FALlon, R.J. (1979) Yersinia enterocolitica epidemiology and antibiotic susceptibility. Journal of Antimicrobial Chemo- $\vec{\circ}$ therapy, 5, 241.

Perera, M.R., Kirk, A. \& Noone, P. (1980) Presentation, diagnosis and management of liver abscess. Lancet, ii, 629. 